\title{
Water Molecules in Carbon 70, $\left(\mathrm{H}_{2} \mathrm{O}\right)_{3} @ \mathrm{C}_{70}$
}

\author{
M. Baskar1 ${ }^{1}$ N. Sathyan ${ }^{2}$ \\ ${ }^{1}$ Central Forensic Science Laboratory, Directorate of Forensic Science Services, Ministry of Home Affairs, Govt. of India, \\ Bhopal, India \\ ${ }^{2}$ Humanity and Science Department, KG Reddy College of Engineering \& Technology, Moinabad, Telangana, India \\ Email: munubas@yahoo.com
}

How to cite this paper: Baskar, M. and Sathyan, N. (2020) Water Molecules in Carbon 70, $\left(\mathrm{H}_{2} \mathrm{O}\right)_{3} @ \mathrm{C}_{70}$. Journal of Biophysical Chemistry, 11, 15-25.

https://doi.org/10.4236/jbpc.2020.112002

Received: April 21, 2020

Accepted: May 22, 2020

Published: May 25, 2020

Copyright $\odot 2020$ by author(s) and Scientific Research Publishing Inc. This work is licensed under the Creative Commons Attribution International License (CC BY 4.0).

http://creativecommons.org/licenses/by/4.0/ (c) (i) Open Access

\begin{abstract}
Endohedral fullerene studies are the fascinating one, particularly with Carbon 60 and Carbon 70. Water molecules inside fullerenes alter their cage structure, reorientations make them to play a lot in charge distribution. In this line we are presenting our work on Carbon 70 with three water molecules inside. $\mathrm{Ab}$ initio SCF calculations are carried out for the fullerene Carbon 70 and Carbon 70 with three water molecules. Carbon 70 is a rugby ball structure, when three water molecules are added inside it, dissociation of charges takes place. Unusual flip flop circular hydrogen bond formation takes place inside Carbon 70. The dipole moment of endohedral $\mathrm{C}_{70}$ with three water molecules has been found to be 0.53 Debye, 0.49 Debye and 0.71 Debye respectively for STO-3G, 3-21G and 6-31G basis sets. Total energies for this molecule are reported in addition to the Hydrogen bond length and bond angles of the three water molecules trapped inside $\mathrm{C}_{70}$.
\end{abstract}

\section{Keywords}

Carbon 70, $\left(\mathrm{H}_{2} \mathrm{O}\right)_{3} @ \mathrm{C}_{70}$ : Endohedral Fullerene, Ab Initio,

Self Consistent Field, Dipole Moment

\section{Introduction}

Theoretical predictions of buckyball molecules appeared in literature between 1960 and 1970. Carbon 70 was discovered in 1985 by Robert Curl, Harold Kroto and Richard Smalley using laser evaporation of graphite. They found $\mathrm{C}_{\mathrm{n}}$ clusters $(n>20)$ of which the most common were $\mathrm{C}_{60}$ and $\mathrm{C}_{70}$. For this discovery they have been awarded Nobel Prize in 1996. Carbon 70 molecule, which is one type of fullerene is a cage like fused ring structure, resembles like a rugby ball. $\mathrm{C}_{70}$ is made by 25 hexagons and 12 pentagons. Endohedral fullerenes also called as endofullerenes are fullerenes that have additional atoms, ions, clusters enclosed 
within their inner spheres. First lanthanum $\mathrm{C}_{60}$ complex was synthesized in 1985 and called as $\mathrm{La}_{0} \mathrm{C}_{60}$ [1]. $\mathrm{C}_{60}$ with one water molecule [2] [3] [4] and three water molecule [5] [6] are reported. Also, $\mathrm{C}_{70}$ with two water molecules [7] is also reported. In this work three water molecules that are included inside $\mathrm{C}_{70}$ are reported and can be called as $\left(\mathrm{H}_{2} \mathrm{O}\right)_{3} @ \mathrm{C}_{70}$. Calculations are carried out at SCF ab-initio STO-3G, 3-21G and 6-31G basis sets.

\section{Methods of Calculation}

Computations of Self Consistent Field ab-initio calculations are carried out with STO-3G, 3-21G and 6-31G basis sets. Computations package, Firefly [8] [9] and Avogadro [10] are used.

\section{Results}

The structure of fullerene $\mathrm{C}_{70}$ and the structure of Carbon 70 with three waters molecules inside are shown in Figure 1 and Figure 2 respectively. Optimized geometry calculations are carried out at SCF ab-initio STO-3G, 3-21G and 6-31G basis sets. Total energies of these molecules are given in Table 1 in atomic units.

Optimized $\mathrm{C}_{70}$ with 3 water molecules at $3-21 \mathrm{G}$ basis set is reported in the Figure 2. Cyclic hydrogen bonds involving flipping action inside Carbon 70 with 3 water molecules at $3-21 \mathrm{G}$ basis set with bond lengths and oxygen angles is shown in Figure 3. The bond length of one oxygen atom to the hydrogen atom of other water molecule and vice versa is $1.52 \AA, 1.53 \AA$ and $1.64 \AA$ and the angle with respect to the oxygen of each water molecule is $57.55^{\circ}, 64.96^{\circ}$ and $57.48^{\circ}$ respectively.

Structure of $\mathrm{C}_{70}$ with $3 \mathrm{H} 2 \mathrm{O}$ molecules optimised at 3-21G basis set

Cyclic water molecules having anchored and deflected with one hydrogen atom in each molecule, angles formed among water molecules after optimisation at 3-21G basis set are shown in Figure 4. The angles in respect of anchored and deflected hydrogen atom in each water molecule are $49.41^{\circ}, 79.65^{\circ}$ and $50.93^{\circ}$, $60.67^{\circ}, 61.88^{\circ}$ and $57.46^{\circ}$ respectively. The angle of water molecule is of $109.82^{\circ}$, $105.69^{\circ}$ and $107.15^{\circ}$.

The optimized structure at $6-31 \mathrm{G}$ basis set of $\mathrm{C}_{70}$ with 3 water molecules reported and the conformation of water molecules with hydrogen bonding in cyclic manner along with their bond lengths and oxygen bond angles are shown in Figure 5, Figure 6(a) and Figure 6(b) respectively. The bond length of one oxygen atom to the hydrogen atom of other water molecule and vice versa is $1.63 \AA$, $1.63 \AA$ and $1.70 \AA$ and the angle with respect to the oxygen of each water molecule is $57.64^{\circ}, 65.85^{\circ}$ and $56.51^{\circ}$ respectively.

\section{Structure of $\mathrm{C}_{70}$ with $3 \mathrm{H} 2 \mathrm{O}$ molecules optimised at 6-31G basis set}

Cyclic water molecules having anchored and deflected with one hydrogen atom in each molecule and the angles formed among water molecules after optimized at 6-31G basis set. The angles in respect of anchored and deflected hydrogen atom in each water molecule are $49.08^{\circ}, 85.29^{\circ}$ and $45.63^{\circ}, 60.76^{\circ}, 61.24^{\circ}$ $\& 58.00^{\circ}$ and the angle of water molecule is of $112.17^{\circ}, 107.37^{\circ}$ and $109.48^{\circ}$ respectively shown in Figure 7(a) and Figure 7(b). 


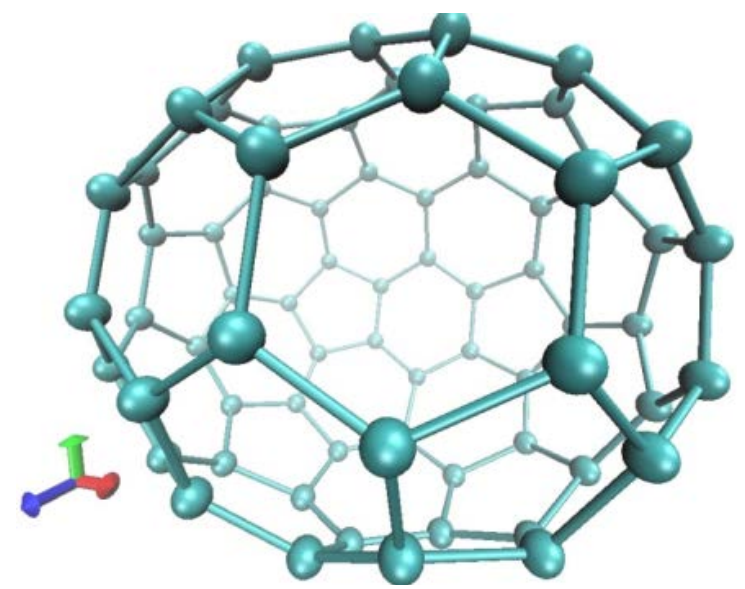

Figure 1. Carbon 70.

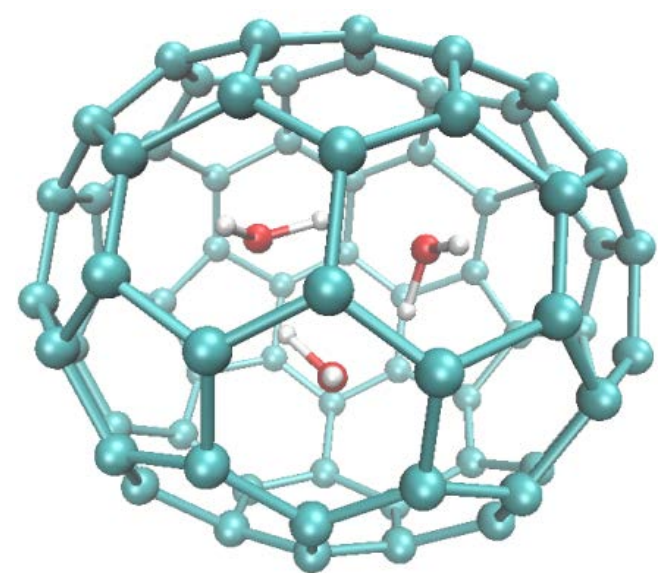

Figure 2. Optimised Structure of Carbon 70 with three water molecules at 3-21G basis set.

Table 1. Total energy of the molecules in atomic units (AU).

\begin{tabular}{cccc}
\hline Molecules & STO-3G Basis Set & 3-21 G Basis set & 6-31 G Basis set \\
\hline CARBON 70 & -2618.357389 & -2843.170273 & 2649.574118 \\
$\left(\mathrm{H}_{2} \mathrm{O}\right)_{3} @ \mathrm{C}_{70}$ & -2635.636499 & -2862.366387 & -2877.425062 \\
\hline
\end{tabular}

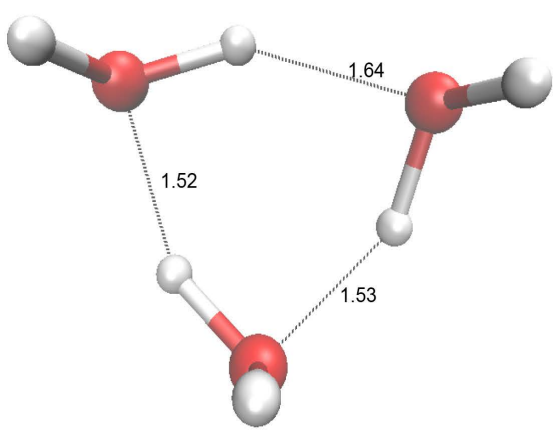

(a)

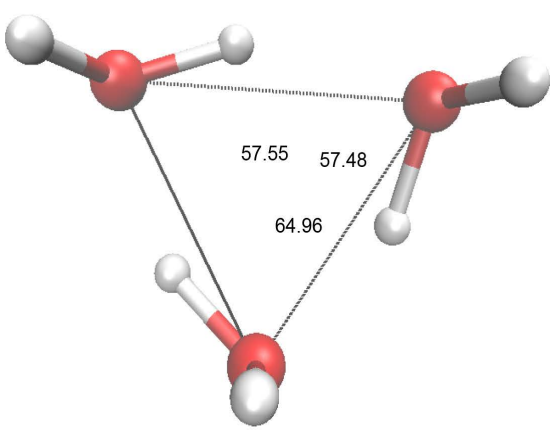

(b)

Figure 3. (a) Hydrogen Bond lengths in $\AA$ and (b) Oxygen bond angles in ’. 


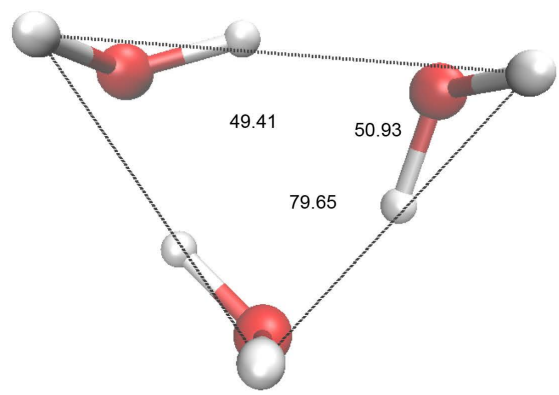

(a)

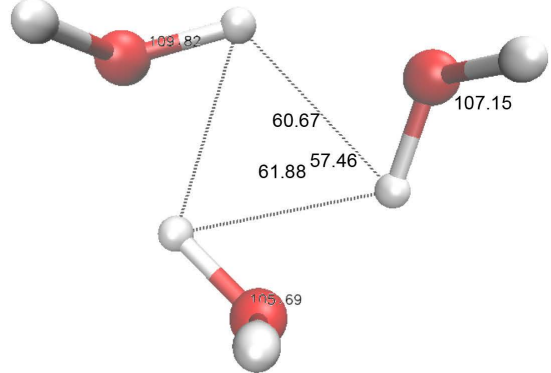

(b)

Figure 4. (a) Angles of anchored hydrogen atoms and (b) Angles of deviated hydrogen atoms of water molecules encapsulated in $\mathrm{C}_{70}$.

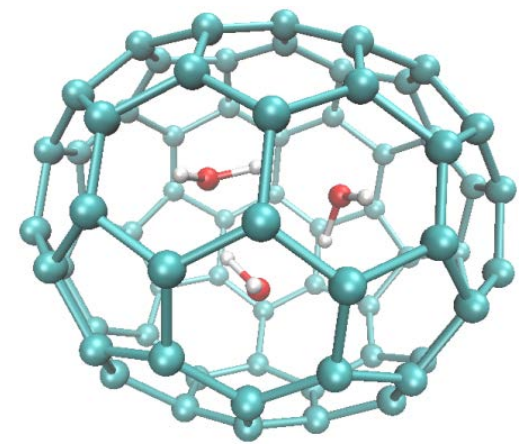

Figure 5. Optimised structure of $\mathrm{C}_{70}$ encapsulated with three water molecules at 6-31G basis set.

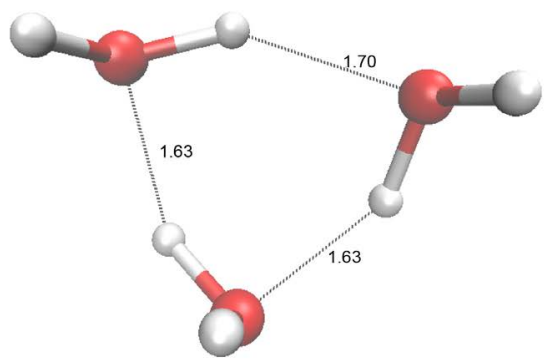

(a)

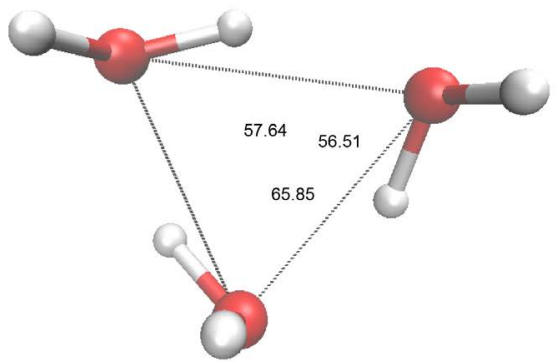

(b)

Figure.6. (a) Hydrogen bond lengths and (b) Oxygen bond angles.

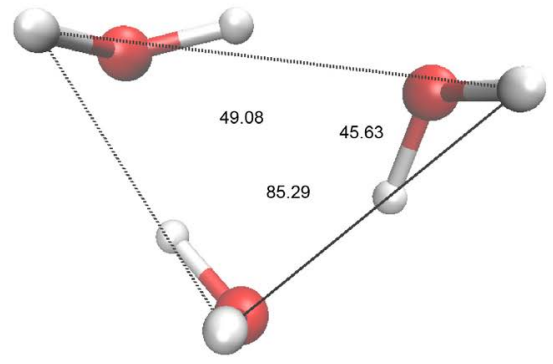

(a)

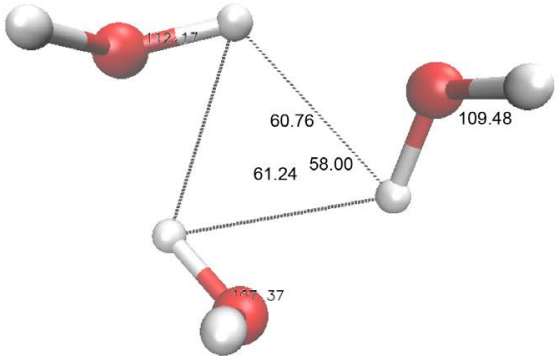

(b)

Figure 7. (a) Angles of anchored hydrogen atoms and (b) Angles of deviated hydrogen atoms of water molecules encapsulated in $\mathrm{C}_{70}$. 


\section{Discussion}

The pentagons and hexagons of the rugby ball structure of fullerene $\mathrm{C}_{70}$ as shown Figure 1 are adopted to have the usual bond lengths and bond angles as reported experimentally. Due to the inclusion of water molecules as shown in Figure 2, $\mathrm{C}_{70}$ structure is slightly modified and the formation of dipole moment is seen. Dipole moment has been found to be 0.53 Debye, 0.49 Debye and 0.71 Debye respectively for STO-3G, 3-21G and 6-31G basis sets. Dipole moment is the indication of conductivity and magnetism. Three water molecules inside $\mathrm{C}_{70}$ interact with each other through hydrogen bonding. One hydrogen of the water molecule interact with Oxygen of other water molecule respectively through bonding in cyclic, which makes themselves as a cyclic water trimer. Water trimer exhibits ortho metastable configuration inside $\mathrm{C}_{70}$, rather para configuration when it is outside the rugby ball [11].

This study is in line with our previous work on circular and linear hydrogen bonds on molecules [5] [6] [12] [13] [14] [15]. Fullerenes and Endohedral fullerenes will find a lot of applications in conductivity, magnetism, drug delivary, photovoltics and storing atoms and molecules. It seems to be finding applications in sensing, cosmetics and medicinal fields. This kind of studies will help to achieve the above applications.

\section{3-21 G basis set Calculation on $\left(\mathrm{H}_{2} \mathrm{O}\right)_{3} @ \mathrm{C}_{70}$}

One hydrogen atom of all the three water molecules $(\mathrm{H}-\mathrm{O}-\mathrm{H})$ encapsulated in the endohedral fullerene is anchored with respect to $\mathrm{H}-\mathrm{O}$ - in a triangle forming among themselves, as shown in Figure 4(a), in an angle $\mathrm{H}-\mathrm{H}-\mathrm{H}$ is $49.41^{\circ}, 79.65^{\circ}$ and $50.93^{\circ}$ respectively which are altogether and considerably different from the same anchored angle of $\mathrm{H}-\mathrm{H}-\mathrm{H}$ in $\left(\mathrm{H}_{2} \mathrm{O}\right)_{3} @ \mathrm{C}_{60}$ [5] [6] i.e. $61.89^{\circ}, 57.17^{\circ}$ and $60.94^{\circ}$. On the other hand, the other hydrogen atom is deflected in all the three water molecules with respect to $-\mathrm{O}-\mathrm{H}$ and the angle between the deflected hydrogens is $60.67^{\circ}, 61.88^{\circ}$ and $57.46^{\circ}$ respectively, as shown in Figure 4(b), which are very little change similarities from the angle of $\mathrm{H}-\mathrm{H}-\mathrm{H}$ in $\left(\mathrm{H}_{2} \mathrm{O}\right)_{3} @ \mathrm{C}_{60}$ [5] [6] i.e. $59.90^{\circ}, 60.26^{\circ}$ and $59.84^{\circ}$. The bond length between the deflected hydrogen atom of one water molecule and the oxygen of the second water molecule, deflected hydrogen of second water molecule and the oxygen of the third water molecule and deflected hydrogen of third water molecule and the oxygen of the first water molecule have been observed respectively as $1.52 \AA, 1.53 \AA$ and $1.64 \AA$ as shown in Figure $3(\mathrm{a})$. The ab-initio calculations of Fullerene $\mathrm{C}_{70}$, Water trimer and Water trimer encapsulated fullerene in three different levels of basis sets, STO-3G, 3-21G and 6-31G, using RHF have been taken place and their optimised and the total energy for stabilizing the molecules is presented as shown in the Table 1. Water molecules in the endohedral fullerene adopt an angle is $109.82^{\circ}, 105.69^{\circ}$ and $107.15^{\circ}$ and their bond length as defined in the Figure $3(\mathrm{~b})$ and Table 2 respectively. The angles of each of the water molecules and their bond lengths are having little deviation from their corresponding experimental values for gas phase, $\mathrm{O}-\mathrm{H}$ length is $0.95718 \AA$ and the $\mathrm{H}-\mathrm{O}-\mathrm{H}$ angle is $104.474^{\circ}$ [16] and liquid water, O-H length $0.991 \AA$, $\mathrm{H}-\mathrm{O}-\mathrm{H}$ angle $105.5^{\circ}$ and $106.0^{\circ}$ [17] [18]. 
Table 2. Bond length $(\AA)$ and Bond angles $\left(^{\circ}\right)$ of three water molecules in $C_{70}$ encapsulated, optimized at 3-21G basis set and 6-31G basis set.

\begin{tabular}{|c|c|c|c|c|c|}
\hline \multicolumn{3}{|c|}{ 3-21 G basis set } & \multicolumn{3}{|c|}{ 6-31 G basis set } \\
\hline \multirow{3}{*}{$\begin{array}{l}\text { Water Molecule } \\
\mathrm{H}_{11}-\mathrm{O}_{1}-\mathrm{H}_{12}\end{array}$} & \multicolumn{2}{|c|}{$\begin{array}{l}\text { Bond Angle in } \% \\
\text { Bond Length in } \AA\end{array}$} & \multirow{3}{*}{$\begin{array}{l}\text { Water Molecule } \\
\mathrm{H}_{11}-\mathrm{O}_{1}-\mathrm{H}_{12}\end{array}$} & \multicolumn{2}{|c|}{$\begin{array}{l}\text { Bond Angle in } \% \\
\text { Bond Length in } \AA\end{array}$} \\
\hline & \multicolumn{2}{|c|}{$109.82^{\circ} 107.15$} & & \multicolumn{2}{|c|}{$112.17^{\circ}$} \\
\hline & \multicolumn{2}{|c|}{$0.96 \quad 0.99$} & & \multicolumn{2}{|c|}{$0.94 \quad 0.96$} \\
\hline \multirow{2}{*}{$\mathrm{H}_{21}-\mathrm{O}_{2}-\mathrm{H}_{22}$} & \multicolumn{2}{|c|}{$105.69^{\circ}$} & \multirow{2}{*}{$\mathrm{H}_{21}-\mathrm{O}_{2}-\mathrm{H}_{22}$} & \multicolumn{2}{|c|}{$107.37^{\circ}$} \\
\hline & 0.99 & 0.96 & & 0.96 & 0.95 \\
\hline \multirow{2}{*}{$\mathrm{H}_{31}-\mathrm{O}_{3}-\mathrm{H}_{33}$} & \multicolumn{2}{|c|}{$107.15^{\circ}$} & \multirow{2}{*}{$\mathrm{H}_{31}-\mathrm{O}_{3}-\mathrm{H}_{33}$} & \multicolumn{2}{|c|}{$109.48^{\circ}$} \\
\hline & 0.96 & 0.99 & & 0.96 & 0.94 \\
\hline \multirow[t]{2}{*}{$\mathrm{O}_{1}-\mathrm{O}_{2}-\mathrm{O}_{3}$} & \multicolumn{2}{|c|}{$57.55^{\circ}$} & \multirow[t]{2}{*}{$\mathrm{O}_{1}-\mathrm{O}_{2}-\mathrm{O}_{3}$} & \multicolumn{2}{|c|}{$57.64^{\circ}$} \\
\hline & 2.53 & 2.36 & & 2.57 & 2.35 \\
\hline $\mathrm{O}_{2}-\mathrm{O}_{3}-\mathrm{O}_{1}$ & \multicolumn{2}{|c|}{$64.96^{\circ}$} & $\mathrm{O}_{2}-\mathrm{O}_{3}-\mathrm{O}_{1}$ & \multicolumn{2}{|c|}{$65.852^{\circ}$} \\
\hline $\mathrm{O}_{3}-\mathrm{O}_{1}$ & \multicolumn{2}{|c|}{2.53} & $\mathrm{O}_{3}-\mathrm{O}_{1}$ & \multicolumn{2}{|c|}{2.38} \\
\hline $\mathrm{O}_{3}-\mathrm{O}_{1}-\mathrm{O}_{2}$ & \multicolumn{2}{|c|}{$57.48^{\circ}$} & $\mathrm{O}_{3}-\mathrm{O}_{1}-\mathrm{O}_{2}$ & \multicolumn{2}{|c|}{$56.51^{\circ}$} \\
\hline $\mathrm{O}_{1}-\mathrm{H}_{21}$ & \multicolumn{2}{|c|}{1.64} & $\mathrm{O}_{1}-\mathrm{H}_{21}$ & \multicolumn{2}{|c|}{1.70} \\
\hline $\mathrm{O}_{2}-\mathrm{H}_{31}$ & \multicolumn{2}{|c|}{1.52} & $\mathrm{O}_{2}-\mathrm{H}_{31}$ & \multicolumn{2}{|c|}{1.63} \\
\hline $\mathrm{O}_{3}-\mathrm{H}_{11}$ & \multicolumn{2}{|c|}{1.53} & $\mathrm{O}_{3}-\mathrm{H}_{11}$ & & \\
\hline $\mathrm{H}_{12}-\mathrm{H}_{22}-\mathrm{H}_{33}$ & & & $\mathrm{H}_{12}-\mathrm{H}_{22}-\mathrm{H}_{33}$ & & \\
\hline Anchored & 2.55 & 2.50 & Anchored & 3.29 & 2.36 \\
\hline $\mathrm{H}_{22}-\mathrm{H}_{33}-\mathrm{H}_{12}$ & & & $\mathrm{H}_{22}-\mathrm{H}_{33}-\mathrm{H}_{12}$ & & $29^{\circ}$ \\
\hline Anchored & & & Anchored & & 50 \\
\hline$\underset{\text { Anchored }}{\mathrm{H}_{33}-\mathrm{H}_{12}-\mathrm{H}_{22}}$ & & & $\begin{array}{c}\mathrm{H}_{33}-\mathrm{H}_{12}-\mathrm{H}_{22} \\
\text { Anchored }\end{array}$ & & $53^{\circ}$ \\
\hline $\mathrm{H}_{12}-\mathrm{H}_{22}-\mathrm{H}_{33}$ & & & $\mathrm{H}_{12}-\mathrm{H}_{22}-\mathrm{H}_{33}$ & & \\
\hline Deflected & 1.89 & 1.81 & Deflected & 1.97 & 1.91 \\
\hline $\mathrm{H}_{22}-\mathrm{H}_{33}-\mathrm{H}_{12}$ & & & $\mathrm{H}_{22}-\mathrm{H}_{33}-\mathrm{H}_{12}$ & & \\
\hline Deflected & & & Deflected & & 96 \\
\hline$\underset{\text { Deflected }}{\mathrm{H}_{33}-\mathrm{H}_{12}-\mathrm{H}_{22}}$ & & & $\underset{\text { Deflected }}{\mathrm{H}_{33}-\mathrm{H}_{12}-\mathrm{H}_{22}}$ & & \\
\hline
\end{tabular}

All the three water molecules are stabilized by interacting with their hydrogens among themselves and also with carbons of fullerenes $\mathrm{C}_{70}$. Four hydrogens of two water molecules are interacting with six membered ring of $\mathrm{C}_{70}$ and two hydrogens of one water molecule is interacting with five membered ring of the $\mathrm{C}_{70}$ as shown in Figure 8(a). The overall optimized fullerene $\mathrm{C}_{70}$ structure is related to oval in shape and the diameter of the fullerene alongside of the oval is $8.25 \AA$ and their minimum diameter other than the oval side is $6.98 \AA$ as shown in Figure 8 (b). The spatial orientation of atoms (anchored hydrogens, deviated hydrogens and oxygens) in all the three water molecules within $\mathrm{C}_{70}$ are altogether are in different planes and parallel to each other.

The hydrogen atoms and oxygen atoms of all the three water molecules are stabilized by maximally interacting with six membered rings of the fullerene molecule in range of the distance from $2.5 \AA$ to $2.9 \AA$. Graphical representations of the molecule are referred by Visual Molecular Dynamics software Package [19]. 


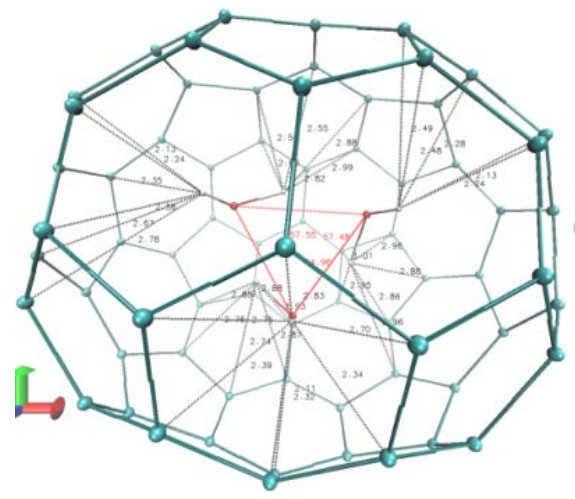

(a)

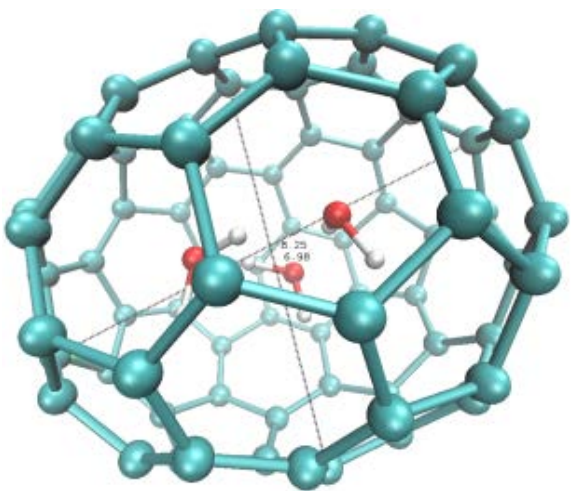

(b)

Figure 8. (a) Length of $\mathrm{C}_{70}$ optimised at $3-21 \mathrm{G}$ and (b) Interactions of the six hydrogens of 3 waters molecules with $\mathrm{C}_{70}$.

\section{6-31 G basis set Calculation $\left(\mathrm{H}_{2} \mathrm{O}\right)_{3} @ \mathrm{C}_{70}$}

One hydrogen atom of all the three water molecules ( $\mathrm{H}-\mathrm{O}-\mathrm{H})$ encapsulated in the endohedral fullerene is anchored with respect to $\mathrm{H}-\mathrm{O}$ - in a triangle among themselves in an angle $\mathrm{H}-\mathrm{H}-\mathrm{H}$ is $49.08,85.29^{\circ}$ and $45.63^{\circ}$ respectively which are about $12.81^{\circ}, 28.12^{\circ}$ and $15.31^{\circ}$ differ from the same angle of $\mathrm{H}-\mathrm{H}-\mathrm{H}$ in $\left(\mathrm{H}_{2} \mathrm{O}\right)_{3} @ \mathrm{C}_{60}$ [5] [6] as shown in Figure 6(b). On the other hand, the other hydrogen atom is deflected in all the three water molecules with respect to $-\mathrm{O}-\mathrm{H}$ and the angle between the deflected hydrogens is $60.76^{\circ}, 61.24^{\circ}$ and $58.00^{\circ}$ respectively which are very little change similarities, as shown in Figure 7, from the angle of $\mathrm{H}-\mathrm{H}-\mathrm{H}$ in $\left(\mathrm{H}_{2} \mathrm{O}\right)_{3} @ \mathrm{C}_{60}$ [5] [6]. The bond length between the deflected hydrogen atom of one water molecule and the oxygen of the second water molecule, deflected hydrogen of second water molecule and the oxygen of the third water molecule and deflected hydrogen of third water molecule and the oxygen of the first water molecule have been observed respectively as $1.63 \AA$, $1.63 \AA$ and $1.70 \AA$ respectively as shown in Figure 6(a). The ab-initio calculations of Fullerene $\mathrm{C}_{70}$, Water trimer and Water trimer encapsulated fullerene in three different levels of basis sets, STO-3G, 3-21G and 6-31G, using RHF have been taken place and their optimized and the total energy for stabilizing the molecules is presented as shown in the Table 1. Water molecules in the endohedral fullerene adopt an angle is $112.17^{\circ}, 107.34^{\circ}$ and $109.48^{\circ}$ and their bond length as defined in Figure 7 and Table 2. All the three water molecules are stabilized by interacting with their hydrogens among themselves and also with carbons of fullerenes $\mathrm{C}_{70}$. Four hydrogens of two water molecules are interacting with six membered ring of $\mathrm{C}_{70}$ and two hydrogens of one water molecule is interacting with partially with both the five and six membered ring of the $\mathrm{C}_{70}$ as shown in Figure 9(a). The overall optimized fullerene $C_{70}$ structure optimized at 631-G is also related to oval in shape and the maximum diameter of the fullerene alongside of the oval is $8.26 \AA$ and their maximum diameter other than the oval side is $6.98 \AA$ as shown in Figure 9(b). The spatial orientation of atoms (i.e. anchored hydrogen, deviated hydrogen and oxygen) in all the three water molecules within $\mathrm{C}_{70}$ are altogether existing in different planes and parallel to each other. 


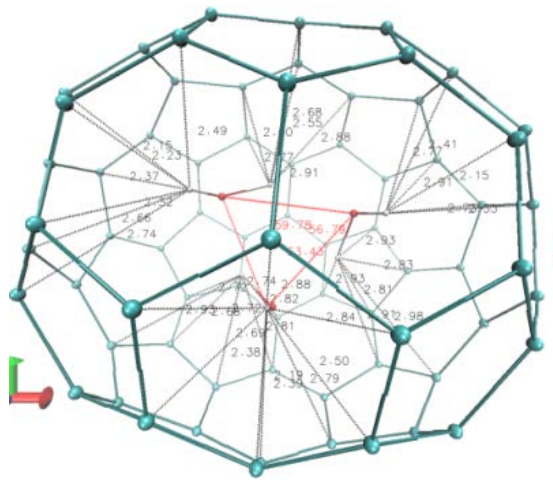

(a)

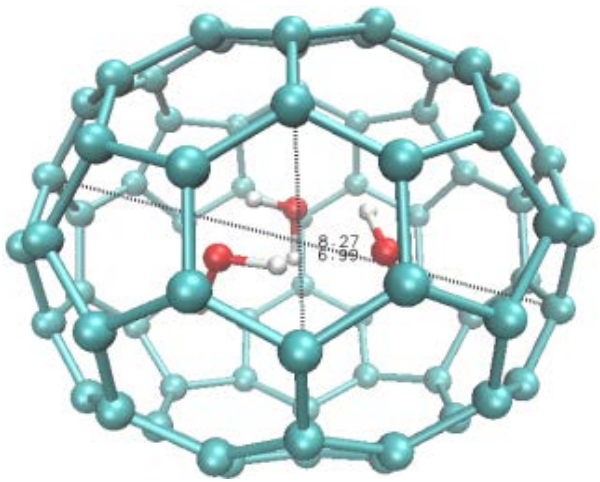

(b)

Figure 9. (a) Length of $C_{70}$ optimised at 6-31G and (b) Interactions of the six hydrogen of 3 waters molecules with $\mathrm{C}_{70}$.

\section{Comparison of optimised $\mathrm{C}_{70}$ with three water molecules at 3-21G and} 6-31G basis sets

Comparing the endohedral fullerene $\left(\mathrm{H}_{2} \mathrm{O}\right)_{3} @ \mathrm{C}_{70}$ structure at 3-21G and 6-31G basis sets, it is found that having maximum similarities. In contrary the water molecules adopts their position among themselves are meagerly deflective through their oxygen and hydrogen bonds as show in Figure 10 \& Figure 11. There is also a dissimilarity of their bond lengths. The orientations of the water molecules encapsulated in $\mathrm{C}_{60}$ [5] [6] with comparison of the water molecules encapsulated in $\mathrm{C}_{70}$ optimized both at 3-21G and 6-31G basis sets are considerably different in their various angles and bond lengths as discussed. The hydrogen and oxygen bond deviations in respect of the water molecules optimized at 3-21G and 6-31G basis set is shown in Figure 10 \& Figure 11.

The spacial orientation of atoms (i.e. anchored hydrogen, deviated hydrogen and oxygen) in all the three water molecules within $\mathrm{C}_{70}$ level are altogether existing in different planes and parallel to each other separately but high probable similarities could be observed among the water molecules at 3-21 G and 6-31 G by measuring the differences as detailed in Table 3 .

The length of deviations among bond lengths and angles of all the three water molecules in $\mathrm{C}_{70}$ is as shown in Figure 12 and in Table 3.

\section{Conclusion}

SCF ab initio Calculations on fullerenes $\mathrm{C}_{70}$ and endohedral fullerene $\left(\mathrm{H}_{2} \mathrm{O}\right)_{3} @$ $\mathrm{C}_{70}$ shows a promising beginning to find out the structural reorientation in equilibrium geometries. Spacial orientations of atoms in water molecules within $\mathrm{C}_{70}$ show three different planes. Charges need refinements. This result is in line with our previous ab-initio calculation with $\left(\mathrm{H}_{2} \mathrm{O}\right)_{3} @ \mathrm{C}_{60}$. The study on seven endofullerene, ${\mathrm{M} @ \mathrm{C}_{60}}_{6}$ ), Where $\mathrm{M}=\mathrm{H} 2 \mathrm{O}, \mathrm{Li}+, \mathrm{Na}+, \mathrm{K}+, \mathrm{Be} 2+, \mathrm{Mg} 2+$, and $\mathrm{Ca} 2+$ were also reported [20] and concluded that all of the endofullerenes are more stable than pure C60. Coupled translational and rotational motions of $\mathrm{H} 2$ molecules in $\mathrm{C}_{70}$ and $\mathrm{C} 60$ has been reported [21] with the predictions that at most two $\mathrm{H} 2$ molecules can stably occupy $\mathrm{C}_{70}$ and just one can be accommodated by $\mathrm{C}_{60}$ which are 
Table 3. Length of deviations in bond length and bond angles of trimer water molecules in $\mathrm{C}_{70}$ encapsulated at 3-21G and 6-31G basis set.

\begin{tabular}{|c|c|c|c|}
\hline \multirow[t]{2}{*}{ Water Molecule } & \multicolumn{2}{|c|}{$\mathrm{H}-\mathrm{H}$} & \multirow{2}{*}{$\mathrm{O}-\mathrm{O}$} \\
\hline & 1 & 2 & \\
\hline 1 & 0.05 & 0.11 & 0.10 \\
\hline 2 & 0.20 & 0.07 & 0.15 \\
\hline 3 & 0.15 & 0.20 & 0.92 \\
\hline
\end{tabular}
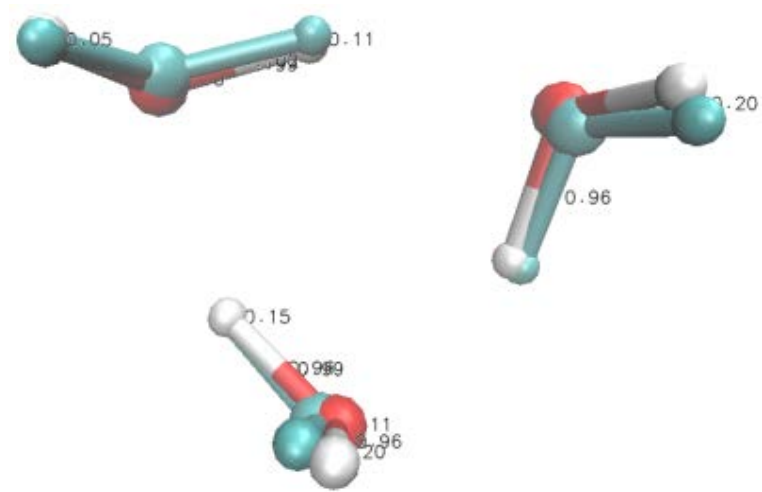

Figure 10. Orientation of water molecules inside $C_{70}$, Optimised at 3-21G and 6-31G basis sets.
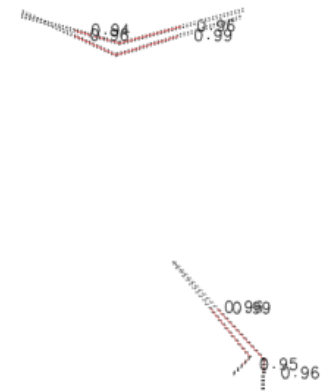
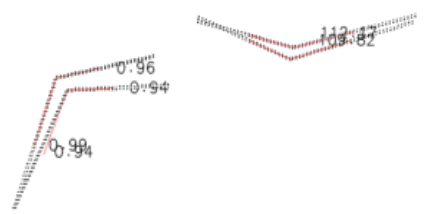

107.15
109.48

Figure. 11. Bond length $(\AA)$ and Angle $\left({ }^{\circ}\right)$ of water molecules inside $\mathrm{C}_{70}$ at $3-21 \mathrm{G}$ and 6-31G basis sets.
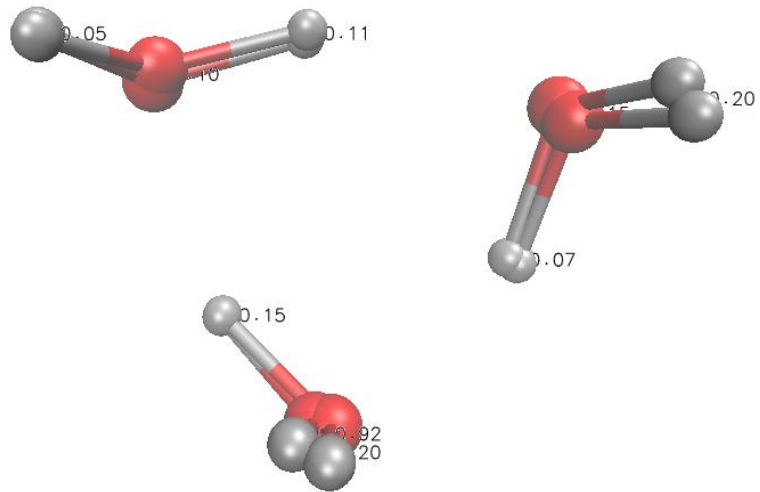

Figure 12. Deviations of bond length in $\AA$ and bond angle in degrees among three water molecule inside $\mathrm{C}_{70}$, optimized at 3-21G basis set and 6-31G basis set. 
in accord with the experimental preparation of $\left.\left(\mathrm{H}_{2}\right) \mathrm{n} @ \mathrm{C}_{70}(\mathrm{n}) 1,2\right) 4$ and $\mathrm{H}_{2} @ \mathrm{C}_{60}$ [22] [23]. At the same Experimental value of dipole moment of one water encapsulated fullerene also supports this kind of work, but a lot of experimental work should be carried out for further endeavours. This kind of studies will help endohedral fullerenes to achieve the applications in the field of sensors, super conductivity, medicine, magnetism, storing, photovoltic and drug delivery, etc.

\section{Acknowledgements}

The authors are acknowledging the support rendered by 1) Central Forensic Science Laboratory, Bharkheda Bondar, Bairagarh Kalan, Bhopal-462030, Madhya Pradesh, India and 2) Humanity \& Science Department, KG Reddy College of Engineering \& Technology, Moinabad-501504, Telangana, India.

\section{Conflicts of Interest}

The authors declare no conflicts of interest regarding the publication of this paper.

\section{References}

[1] Chai, Y., Guo, T., Jin, C.M., et al. (1991) Fullerenes with Metal Inside. Journal of Physical Chemistry, 95, 7564-7568. https://doi.org/10.1021/j100173a002

[2] Benno, M., Mamone, S. and Levitt, M.H. (2015) Electrical Detection of Ortho-Para Conversion in Fullerene-Encapsulated Water. Nature Communications, 6, Article No. 8112. https://doi.org/10.1038/ncomms9112

[3] Kurotobi, K. and Murata, Y. (2003) A Single Molecule of Water Encapsulated in Fullerene C6060. Science, 333, 613. https://doi.org/10.1126/science.1206376

[4] Xu, B.X. and Chen, X. (2013) Electrical-Driven Transport of Endohedral Fullerene Encapsulating a Single Water Molecule. Physical Review Letters, 110, Article ID: 156103. https://doi.org/10.1103/PhysRevLett.110.156103

[5] Baskar, M., Sathyan, N. and Nair, T. (2018) Water Molecules in the Carbon C60 Confined Space. Journal of Biophysical Chemistry, 9, 15-21.

https://www.scirp.org/journal/paperabs.aspx?paperid=88249 https://doi.org/10.4236/jbpc.2018.92002

[6] Baskar, M. and Sathyan, N. (2018) Water Molecules in the Carbon Confined Space (H2O)3@C60. Nanomedicine and Nanotechnology, 4, Article ID: 000158.

[7] Zhang, R., Murata, M., Aharen, T., Wakamiya, A., Shimoaka, T., Hasegawa, T. and Murata, Y. (2016) Synthesis of a Distinct Water Dimer inside Fullerene $\mathrm{C}_{70}$. Nature Chemistry, 8, 435-441. https://doi.org/10.1038/nchem.2464

[8] Granovsk, A.A. Firefly Version 8.2.0. http://classic.chem.msu.su/gran/firefly/index.html

[9] Schmidt, M.W., Baldridge, K.K., Boatz, J.A., Elbert, S.T., Gordon, M.S., Jenson, J.H., Koseky, S., Matsunaja, N., Nguyen, K.A., Su, S., Wimdus, T.L., Dupvis, M. and Montgomery, J.A. (1993) General Atomic and Molecular Electronic Structure System. Journal of Computational Chemistry, 14, 1347-1363. https://doi.org/10.1002/jcc.540141112

[10] Hanwell, M.D., Curtis, D.E., Lonie, D.C., et al. (2012) Avogadro: An Advanced Semantic Chemical Editor, Visualization, and Analysis Platform. Journal of Cheminformatics, 4, 17. https://doi.org/10.1186/1758-2946-4-17 
[11] Xantheas, S.S. and Dunning Jr., T.H. (1993) The Structure of the Water Trimer from ab Initio Calculations. The Journal of Chemical Physics, 98, 8037. https://doi.org/10.1063/1.464558

[12] Sathyan, N., Santhanam, V. and Sobhanadri, J. (1995) Ab Initio Calculations on Some Binary Systems Involving Hydrogen Bonds. Journal of Molecular Structure: THEOCHEM, 333, 179-189. https://doi.org/10.1016/0166-1280(94)03931-A

[13] Sathyan, N., Santhanam, V., Madhurima, V. and Sobhanadri, J. (1995) Conformational Study on the Binary Mixture Acetone-Methanol Involving H-Bonding. Journal of Molecular Structure THEOCHEM, 342, 187-192. https://doi.org/10.1016/0166-1280(95)90115-9

[14] Madhurima, V., Sathyan, N., Murthy, V.R.K. and Sobhanadri, J. (1998) Dielectric and Conformational Studies of Hydrogen Bonded Acetone and Acetonitrile System. Spectrochimica Acta Part A, 54, 299-304. https://doi.org/10.1016/S1386-1425(97)00235-7

[15] Sathyan, N., Santhanam, V. and Sobhanadri, J. (1996) Conformational Analysis of $\mathrm{N}$-Chloromethylenimine and Its Hydrogen-Bonded Dimers with Water from the Study of Nuclear Quadrupole Interactions. Zeitschrift für Naturforschung A, 51, 534-536. https://doi.org/10.1515/zna-1996-5-628

[16] Isaacs, E.D., Shukla, A., Platzman, P.M., Hamann, D.R., Barbiellini, B., et al. (2000) Compton Scattering Evidence for Covalency of the Hydrogen Bond in Ice. Journal of Physics and Chemistry of Solids, 61, 403-406. https://doi.org/10.1016/S0022-3697(99)00325-X

[17] Hasted, J.B. (1972) Liquid Water: Dielectric Properties. In: Franks, F., Ed., Water, a Comprehensive Treatise: The Physics and Physical Chemistry of Water, Vol. 1, Springer, Boston, 255-309. https://doi.org/10.1007/978-1-4684-8334-5_7

[18] Ichikawa, K., Kamed, Y., Yamaguchi, T., Wakita, H. and Misawa, M. (1991) Neutron-Diffraction Investigation of the Intermolecular Structure of a Water Molecule in the Liquid Phase at High Temperatures. Molecular Physics, 73, 79-86. https://doi.org/10.1080/00268979100101071

[19] Humphrey, W., Dalke, A. and Schulten, K. (1996) VMD: Visual Molecular Dynamics. Journal of Molecular Graphics, 14, 33-38. https://doi.org/10.1016/0263-7855(96)00018-5

[20] de Oliveira, O.V. and da Silva Gonçalves, A. (2014) Quantum Chemical Studies of Endofullerenes (M@C60) Where $\mathrm{M}=\mathrm{H}_{2} \mathrm{O}, \mathrm{Li}^{+}, \mathrm{Na}^{+}, \mathrm{K}^{+}, \mathrm{Be}^{2+}, \mathrm{Mg}^{2+}$, and $\mathrm{Ca}^{2+}$. Computational Chemistry, 2, 51-58. https://doi.org/10.4236/cc.2014.24007

[21] Sebastianelli, F., Xu, M.Z., Bacic, Z., Lawler, R. and Turro, N.J. (2010) Hydrogen Molecules inside Fullerene $\mathrm{C}_{70}$ : Quantum Dynamics, Energetics, Maximum Occupancy, and Comparison with C60. Journal of the American Chemical Society, 132, 9826-9832. https://doi.org/10.1021/ja103062g

[22] Komatsu, K., Murata, M. and Murata, Y. (2005) Encapsulation of Molecular Hydrogen in Fullerene C60 by Organic Synthesis. Science, 307, 238-240. https://doi.org/10.1126/science.1106185

[23] Murata, M., Murata, Y. and Komatsu, K. (2006) Synthesis and Properties of Endohedral C60 Encapsulating Molecular Hydrogen. Journal of the American Chemical Society, 128, 8024-8033. https://doi.org/10.1021/ja061857k 